\title{
Human Immunodeficiency Virus Seroprevalence among Inmates of the Penitentiary Complex of the Region of Campinas, State of São Paulo, Brazil
}

\author{
Neusa Maria Osti, Antonio Fernando Pestana de Castro*/+, \\ Lucila Costallat Ricci**
}

\begin{abstract}
Departamento de Análises Clínicas e Toxicológicas, Faculdade de Ciências Médicas, Pontifícia Universidade Católica de Campinas, Campinas, SP, Brasil *Departamento de Microbiologia, Instituto de Ciências Biomédicas, Universidade de São Paulo, Caixa Postal 66208, 05508-900, São Paulo, SP, Brasil **Departamento de Microbiologia e Imunologia, Universidade Estadual de Campinas, Campinas, SP, Brasil
\end{abstract}

Six hundred and ninety three male inmates from three penitentiaries, two (A and B) maximum-security systems and one $(C)$ minimum-security facility, located in Campinas, State of São Paulo, Brazil were studied for the presence of human immunodeficiency virus (HIV) antibodies, using a cross-sectional design. The search for anti-HIV antibodies in 693 samples of sera collected was carried out by two serological tests: (a) the Microparticle enzyme immunoassay-HIV-1 and HIV-2 (MEIA) (Abbott Laboratories) and (b) the Western Blot-HIV-1 (WB) (Cambridge Biotech Corporation) to confirm positive results with MEIA. Sera reactivity for HIV antibodies was $14.4 \%$. The highest frequency of anti-HIV antibodies was found in the A and B maximum-security prisons: $17 \%$ and $21.5 \%$, respectively. In prison $C$, the frequency of reagents was $10.9 \%$. Seventy three inmates, initially negative in the MEIA test, were checked again five and seven months later. Three of them, all from the maximum-security facilities, became reactive in the MEIA test, with confirmation in the WB, suggesting that serological conversion had occurred after imprisonment.

Key words: human immunodeficiency virus seroprevalence - inmates - Campinas - Brazil

Available literature regarding reported records since 1985 of anti-human imunodeficiency virus (anti-HIV) antibodies among jail inmates is incomplete. Most works including high number of prisoners were carried out in Scotland (Bird et al. 1995), and United States of America (Hoxie et al. 1990, Vlahov et al. 1991) showing, with slight differences, that the frequencies of human immunodeficiency virus (HIV) positive reactions were higher among prisoners than in the normal population, excluding those groups, which are under risk factors pressures (Stark et al. 1995, Carvalho et al. 1996, Zapiola et al. 1996).

Reports about the frequencies of HIV antibodies among prisoners in South America are rare and include mainly studies on either low number of prisoners (Jabatur et al. 1991, Veronesi et al. 1993)

This study was supported by grants provided by Serviço Unificado de Saúde, Conselho Nacional de Desenvolvimento Científico e Tecnólogico (CNPq) and Fundação de Amparo à Pesquisa do Estado de São Paulo.

${ }^{+}$Corresponding author. Fax: +55-11-818-7354. E-mail: apestana@icb.usp.br

Received 5 October 1998

Accepted 20 April 1999 or prisoners with manifested acquired immunodeficiency syndrome (Aids) (Veronesi et al. 1993).

Taking into consideration several risk factors to which male inmates are exposed nowadays (Benezech et al. 1987, Ferrante et al. 1987, Carbajal et al. 1991, Bird et al. 1995, Calzavara et al. 1995, Stark et al. 1995, Carvalho et al. 1996), the main objectives of this study were: (1) to determine the prevalence of HIV antibodies among sera from 693 inmates of the Penitentiary Complex of Campinas, SP, Brazil, from January to August 1995, as detected by an immunoenzymatic assay and the Western blotting, using a cross-sectional design; (2) to compare the influence of the penitentiary system policy, maximum-security (A and B) or minimumsecurity (C) on the infection rates and (3) to verify whether serological conversion has occurred among the inmates within the study period, as well as, if age range could affect HIV infection.

\section{MATERIALS AND METHODS}

This study was performed with the approval of the Ethical Committee of the enrolled institutions and the agreement of all inmates included in this survey.

Sera samples from prisoners and controls were collected using $10 \mathrm{ml}$-vacuum container vials, la- 
beled with the full names of the individuals in order to avoid any kind of contamination of the lab or devices, following Centers for Disease Control and Prevention (CDC) recommendations for processing blood and other human specimens contaminated by HIV (CDC 1983, 1987a, b).

After clotting, the samples of blood were centrifuged at 3,000 rpm for $10 \mathrm{~min}$ and the sera were then carefully transferred to Khan's tubes, with appropriate caps and identification labels. When sera were not examined on the same day, the tubes were stored at $-18^{\circ} \mathrm{C}$, up to testing.

In this study two types of test kits were used for searching anti-HIV -1/2 antibodies: (a) the Microparticle Enzyme Immunoassay (MEIA), 3rd generation (Abbott Laboratories, Illinois, USA), as a screening test and (b) the Western Blot (WB), (Cambridge Biotech Corporation, Worcester, USA) to confirm the positive results in the MEIA tests. To perform the MEIA test the IMx ${ }^{\circledR}$ System from Abbott Laboratories was used, following all the instructions of the manufacturers. The results were considered positive for those sera whose relationship between sample reading and "index" reading was higher than 1,000. Results between 0,900 and 1,100 were indeterminate and those with less than 0,900 were negative.

The WB tests used as a confirmation assay were also conducted according to the recommendations of the manufacturers. The controls showed reactivity for the following bands, corresponding to the antigenic proteins of HIV-1-strong positive control: p17, p24, p31, gp41, p55, p66, gp120 and gp160; weak positive control: p24 and gp160; negative control: no visible band.

The analysis of the results of the WB assays were performed following the standards established by "The Centers for Disease Control and Prevention (CDC)"/Association of State and Territorial Public Health Laboratory Directors (ASTPHLD) with slight modifications as recommended by the kit manufacturers. Briefly, when the band intensity was less than the p24 weak control, the grade of reactivity was considered $+/-$; when the band intensity was stronger than the weak p24 positive control, but less intense than the strong p24 control, the grade of reactivity was read as + , and when the band intensity was greater than the strong p24 control, the grade of reactivity was considered ++. Overall, the examined sera were considered positive in the WB for the presence of anti-HIV antibodies when the reactivity grade was either + or ++ and at least two of the following bands had to be present: gp160, gp120, gp41 or p24. The results were read as indeterminate when the grade of reactivity was $+/$ - and negative when no bands were visible.
Two hundred and two control sera from volunteers whose physical examination did not show any Aids-compatible symptoms and did not belong to any known risk group for this disease were collected.

All the results were statistically evaluated by the Epi Info version 6.0, from October 1994, developed by CDC and kindly provided by the Department of Preventive Medicine and Epidemiology, from the College of Medical Sciences, of the University of Campinas, SP, Brazil.

\section{RESULTS}

One hundred out of 693 sera samples were positive for anti-HIV-1 and HIV-2 antibodies: 45, 17 and 38 for the penitentiaries A, B and C, respectively. None of 202 sera samples from the control population were positive for anti-HIV antibodies, as detected by the MEIA test. Only one serum sample from this group gave an index of 1.123, which was considered indeterminate (data not shown).

The percentage of positive results for anti-HIV antibodies among inmates, detected by the MEIA test, was significantly higher in the maximum-security penitentiaries (A and B), with a total of 62 $(18.1 \%)$ reactive inmates whereas in the Detention Center (C) 38 (10.9\%) individuals were positive for anti-HIV antibodies by the screening test (Table).

All positive sera in the MEIA test were then examined by the WB for the confirmation of the

\section{TABLE}

Prevalence of anti-human immunodeficiency virus (anti-HIV) antibodies in two samples of inmates from high to minimal security penitentiaries from Campinas, SP, Brazil

\begin{tabular}{|c|c|c|c|c|c|}
\hline \multirow{3}{*}{ Type of prison } & \multicolumn{4}{|c|}{ Anti-HIV antibodies } & \multirow{3}{*}{ Total } \\
\hline & \multicolumn{2}{|c|}{ Positive } & \multicolumn{2}{|c|}{ Negative } & \\
\hline & No. & $\%$ & No. & $\%$ & \\
\hline $\begin{array}{l}\text { High security } \\
(A+B)\end{array}$ & 62 & 18.1 & 281 & 81.9 & 343 \\
\hline $\begin{array}{l}\text { Minimal } \\
\text { security (C) }\end{array}$ & 38 & 10.9 & 312 & 89.2 & 350 \\
\hline Total & 100 & 14.4 & 593 & 85.6 & 693 \\
\hline
\end{tabular}

Penitentiaries A and B were maximum-security facilities whereas penitentiary $\mathrm{C}$ was minimal security. Microparticle enzyme immunoassay (MEIA) 3rd generation (Abbott Laboratories, Illinois, USA) performed in the IMX System was used for the detection of anti-HIV antibodies in inmates' sera, following manufacturers' instructions. The results were considered positive for those sera whose ratio of the sample over the reading of the "index" was higher than 1.000.

$(\mathrm{A}+\mathrm{B} \times \mathrm{C}) \mathrm{p}=0.006854(\mathrm{~S}) ; \mathrm{OR}=1.81(1.15<\mathrm{OR}<2.86)$ 
results obtained by the former test. Ninety-seven out of 100 positive samples by the MEIA test were positive in the WB for HIV antibodies, one was negative and two were considered indeterminate. Figure shows some of the results obtained in the WB test. Among the control population, the sample of serum, which gave indeterminate result, when tested by the MEIA test, was negative by the WB technique (data not shown).

The frequency of anti-HIV antibodies with regard to the range between 18 and 68 years of age when 10-year intervals were taken was determined. It was observed that as far as inmates from the three studied penitentiaries were concerned, there was no significant influence of age on the frequency of seropositivity for HIV, suggesting that while in prison, independent of age, all the prisoners were

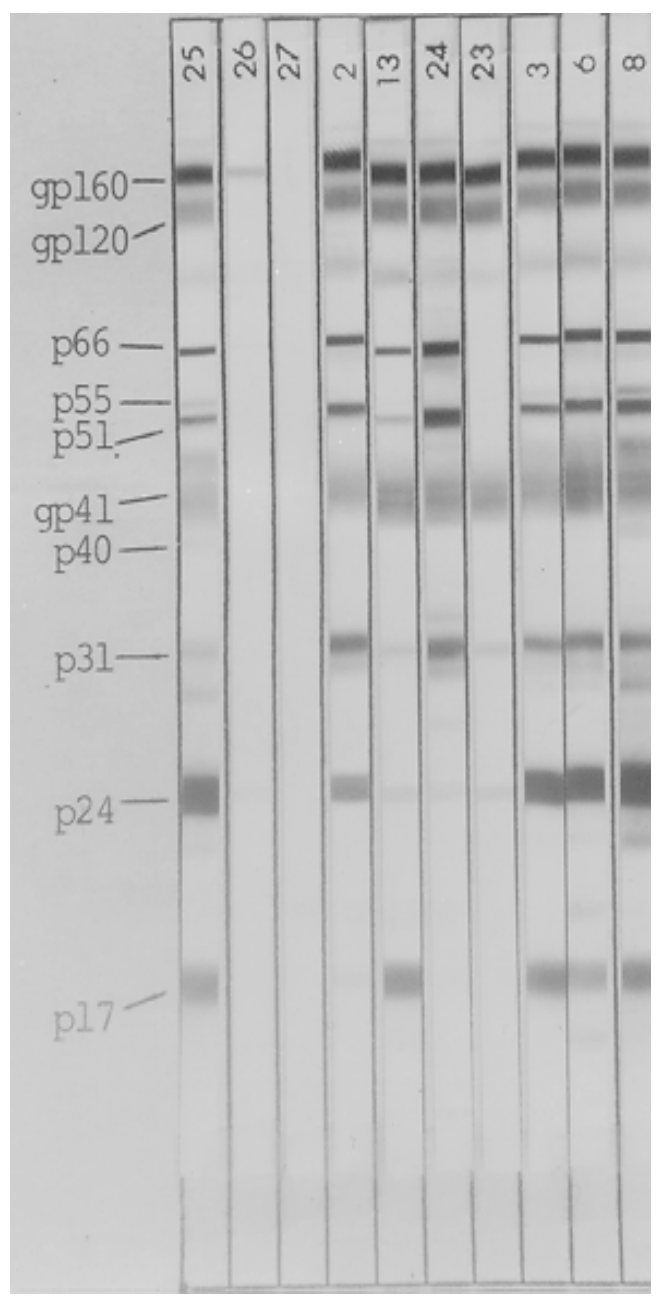

Examples of positive results for anti-human immunodeficiency virus obtained from samples of inmates' sera by Western Blot. 25: strong positive control; 26 : weak positive control; 27 : negative control. Sera 2, 13, 24, 23, 3, 6 and 8 were positive for antiHIV antibodies by the WB. submitted to the same risk factors, increasing the chances of all of them becoming infected by HIV, even the eldest ones (data not shown).

Among 73 inmates who were negative in the first MEIA test, which was performed in the beginning of our research, new samples of sera were collected to follow-up the evolution of the HIV infection within the penitentiaries studied. Three sera, all from penitentiaries A and B (maximumsecurity) became positive in the second test by MEIA, and the results were confirmed by the WB (data not shown).

\section{DISCUSSION}

Comparing the results obtained from prisoners located in maximum-security penitentiaries $(\mathrm{A}+$ B) with those for penitentiary $\mathrm{C}$ (minimum-security), the frequency of anti-HIV antibodies was significantly higher in the former system ( $\mathrm{p}=$ 0.006854 ) demonstrating that the penitentiary system of maximum-security, due to the higher risk factors that the inmates are prone to, may result in a more pronounced HIV infection rate in this penitentiary system. On the other hand, no significant difference was observed in the frequencies of antiHIV antibodies between the penitentiaries of maximum-security system, A x B ( $p=0.36467)$.

The risk factors of contamination by HIV existent in such prisons are usually: (1) spontaneous or forced homosexual activities; (2) heterosexual practices without preservatives during intimate visits; (3) possibility of the use of injected drugs with the use of common non sterilized syringes and needles; (4) accidents with contaminated blood during rebellions and prison overpopulation, being even greater in prisons of maximum safety (Benezech et al. 1987, Ferrante et al. 1987, Carbajal et al. 1991, Bird et al. 1995, Calzavara et al. 1995, Stark et al. 1995, Carvalho et al. 1996). In this reclusion system the inmates are confined during the whole period of sentenced jail time, different from the minimum safety's prisons, where the inmates possess activities and are allowed to work outside the prisons. This fact promotes the development of habits, which differentiates between these two types of inmates. It decreases the time of coexistence among the inmates and the time of stay in the prison, all which render a smaller the risk of contamination mainly by HIV.

Observing the influence of age, taking a 10year interval, we did not get any significant age influence with regard to the frequencies of antiHIV antibodies in inmates between the ages of 18 and $59(\mathrm{p}=0.62878)$, suggesting that within the prisons, age did not influence HIV seropositivity. Conversely, if we look at a report by the Brazilian Ministry of Health (1995), ranging between the 
period of 1980 to 1995 , we realize that anti-HIV antibodies in the general population were more prevalent among those male persons who were sexually active around the ages of 25-29 and 30$34,12,418(21.2 \%)$ and $13,184(22.5 \%)$, respectively. In the same report, the mean frequency of $1.9 \%$ ( 1,903 cases/ 15 years) was observed in male individuals between the ages of 55 and 59 .

The published references about HIV infection and the search for anti-HIV antibodies in our penitentiaries are very poor. Some of the studies were performed with inmates with overt disease (Veronesi et al. 1993) (95.1\%), and thus the percentage of positive results for HIV antibodies was high. In this latter study, the authors also examined about 100 inmates from a small prison in the city of Mogi das Cruzes, State of São Paulo, Brazil, and found $7.5 \%$ of individuals positive for antiHIV antibodies. Another research carried out in the Public Jail of Londrina, State of Paraná, Brazil (Jabatur et al. 1991), reported $6.4 \%$ positive results for anti-HIV antibodies among 158 prisoners. However, the situation in 1991 with regard to jailing conditions in small cities were quite different from those in 1995 and also quite different from the penitentiary complex of Campinas. So, no comparison was valid concerning those data.

If we look at the international literature, it is found that the images, with some variations, are almost the same as ours, but most of them took samples of sera from inmates who had already developed Aids (Horsburgh et al. 1990). Others, as the study by Hoxie et al. (1990) carried out between 1986 and 1988, but published in 1990, concentrated its target much more on the relationship between ingress inmates and intravenous drug users (IVDUs). Almost at the same time, Vlahov et al. (1991) carried out one of the most complete studies among 10,994 ingress inmates in ten different penitentiaries in USA, but the focus was the IVDUs before confinement and consequently cannot be compared with our data with regard to almost 700 inmates, from two different types of prison systems, and whose period of study was not longer than seven months. Similar reports correlating HIV infection among inmates and the IVDUs have been made in other countries (Rotily et al. 1994, Calzavara et al. 1995). In addition, reports of HIV infection among female inmates are rare (Murphy et al. 1992, Hankins et al. 1994) but the data are not different from those reported for male inmates, being the IVDUs the main group of risk, specially while in jails.

In conclusion, our findings were similar to those reported more recently in the seroprevalence of HIV infection among inmates in several parts of the world. However, the present research has shown that the inmates from penitentiaries of maximumsecurity system, as compared to those from minimum-security ones are more likely to become infected by HIV.

\section{REFERENCES}

Benezech M, Rager P, Beylot J 1987. AIDS and hepatitis $\mathrm{B}$ in the prison population: an unavoidable epidemiological reality. Bull Acad Natl Med 171: 215-218.

Bird AG, Gore SM, Cameron SA, Ross AJ, Goldberg DJ 1995. Anonymous HIV surveillance with risk factor elicitation at Scotland's largest prison, Barlinnie. AIDS 9: 801-808.

Brazilian Ministry of Health 1995. Programa Nacional de DST/AIDS 3: 382-386.

Calzavara LM, Major C, Myers T, Schlossberg J, Millson M, Wallace E, Rankin J, Fearon M 1995. Reducing volunteer bias: using leftover specimens to estimate rates of HIV infection among inmates in Ontario, Canada. AIDS 9: 631-637.

Carbajal CL, Vallina E, Arribas JM, Diaz J, Domingues B 1991. Epidemiological study of inmates at risk of AIDS in a Spanish prison. Ann Med Interna (Spain) 8: 382-386.

Carvalho HBD, Mesquita F, Massad E, Bueno RC, Lopes GT, Ruiz MA, Burattini MN 1996. HIV and infections of similar transmission patterns in a drug injector's community of Santos, Brazil. J Acq Imm Def Hum Retrov 12: 84-92.

CDC-Centers for Disease Control 1983. Agent summary statement for human immunodeficiency virus and report on laboratory-acquired infection with HIV. MMWR 37: 1-22.

CDC-Centers for Disease Control 1987a. Human immunodeficiency virus infections in health-care workers exposed to blood of infected patients. $M M W R$ 36: 285-289.

CDC-Centers for Disease Control 1987b. Recommendations for prevention of HIV transmission in healthcare settings. $M M W R$ 36: $1 \mathrm{~S}-18 \mathrm{~S}$.

Ferrante P, Nardi G, Zancheta N, Salvioni PM, Pagano A 1987. Prevalence of HTLV III/LAV and other viral antibodies in normal and at risk population. Boll Inst Sierot Milanese 65: 357-360.

Hankins CA, Gendron S, Handley MA, Richard C, Tung MT, O'Shaughnessy M 1994. HIV infection among women in prison: an assessment of risk factors using a nonnominal methodology. Am J Public Health 84: $1637-1640$.

Horsburgh JR CR, Jarvis JQ, McArther T, Ignacio T, Stock P 1990. Seroconversion to human immunodeficiency virus in prisons inmates. Am J Public Health 80: 209-210.

Hoxie NJ, Vergeront JM, Frisby HR, Pfister JR, Golubjatinikov R, Davis JP 1990. HIV seroprevalence and the acceptance of voluntary HIV testing in incarcerated male prison inmates in Wisconsin. Am J Public Health 80: 1129-1131.

Jabatur A, Baldy JLS, Quesada RMB 1991. Aids, Hepatite B e Sífilis: Prevalência da infecção em 158 presidiários da Cadeia Pública de Londrina, Paraná, Brazil. Rev Soc Bras Med Tropical 24: 169. 
Murphy M, Gaffney K, Carey O, Dooley E, Mulcahy F 1992. The impact of HIV disease on Irish prison population. Int J STD AIDS 3: 426-428.

Rotily M, Galinier-Pujol A, Obadia Y, Moatti JP, Toubiana P, Vernay-Vaisse C, Gastaut JA 1994. HIV testing, HIV infection and associated risk factors among inmates in southeastern French prisons. AIDS 8: 1341-1344.

Stark K, Scheier E, Mueller R, Wirth D, Driesel G, Bienzle U 1995. Prevalence and determinants of antiHCV seropositivity and of HCV genotype among intravenous drugs users in Berlin. Scand J Infect Dis 27: 331-337.

Veronesi R, Camargo Filho FC, Schechtmann M, Neitzer
E, Souza LNX, Zampieri G, Franco BN, Santos O 1993. Aids entre presidiários brasileiros: considerações sobre o possível papel do virus HTLV-I e HBV como co-fatores implicados na patogênese da AIDS. Rev Bras Med 50: 488-496.

Vlahov D, Brewer TF, Castro KG, Narkunas JP, Salive ME, Ullrich J, Muñoz A 1991. Prevalence of antibody to HIV-1 among entrants to US correctional facilities. JAMA 265: 1129-1132.

Zapiola I, Salomone S, Alvarez A, Scolastico MC, Koessel RA, Lemus J, Wainstein C, Muchinik G 1996. HIV-1, HIV-2, HTLV-I/II and STD among female prostitutes in Buenos Aires, Argentina. Eur J Epidemiol 12: 27-31. 
